\title{
Factors affecting the acceptance of blended learning in medical education: application of UTAUT2 model
}

\author{
Seyyed Mohsen Azizi ${ }^{1}$, Nasrin Roozbahani ${ }^{2}$ a and Alireza Khatony ${ }^{3^{*}}$ (D)
}

\begin{abstract}
Background: Blended learning is a new approach to improving the quality of medical education. Acceptance of blended learning plays an important role in its effective implementation. Therefore, the purpose of this study was to investigate and determine the factors that might affect students' intention to use blended learning.

Methods: In this cross-sectional, correlational study, the sample consisted of 225 Iranian medical sciences students. The theoretical framework for designing the conceptual model was the Unified Theory of Acceptance and Use of Technology 2 (UTAUT2). Venkatesh et al. (2012) proposed UTAUT2 as a framework to explain a person's behavior while using technology. Data were analyzed using SPSS-18 and AMOS-23 software. Structural equation modeling technique was used to test the hypotheses.

Results: The validity and reliability of the model constructs were acceptable. Performance Expectance (PE), Effort Expectance (EE), Social Influence (SI), Facilitating Conditions (FC), Hedonic Motivation (HM), Price Value (PV) and Habit (HT) had a significant effect on the students' behavioral intention to use blended learning. Additionally, behavioral intention to use blended learning had a significant effect on the students' actual use of blended learning $(\beta=0.645, P \leq 0.01)$.

Conclusion: The study revealed that the proposed framework based on the UTAUT2 had good potential to identify the factors influencing the students' behavioral intention to use blended learning. Universities can use the results of this study to design and implement successful blended learning courses in medical education.
\end{abstract}

Keywords: Blended learning, UTAUT2, Medical education, Students

\section{Background}

Blended learning can be useful and effective in teaching clinical skills and medical education [1-4]. This approach is a good platform for linking theory and practice in the teaching-learning process [5]. Blended learning or hybrid learning is defined as the systematic integration of face-to-face learning and online learning [6-10]. In the blended learning environment, blending the online

\footnotetext{
*Correspondence: Akhatony@gmail.com

${ }^{3}$ Clinical Research Development Center of Imam Reza Hospital, Kermanshah University of Medical Sciences, Kermanshah, Iran

Full list of author information is available at the end of the article
}

and face-to-face elements should be purposeful. Purposeful blending is defined as blending the tools, methods and technologies to accomplish educational purposes [11]. Some researchers use delivery medium, teaching place, teaching type and synchronicity dimensions to identify blended learning environments. Delivery medium indicates whether education is provided by the technology or the teacher. Teaching place shows whether students receive education in the classroom or online. Teaching type indicates whether content presentation (content-based education) or students' participation (activity-based education) in the learning process is

(c) The Author(s). 2020 Open Access This article is licensed under a Creative Commons Attribution 4.0 International License, which permits use, sharing, adaptation, distribution and reproduction in any medium or format, as long as you give appropriate credit to the original author(s) and the source, provide a link to the Creative Commons licence, and indicate if changes were made. The images or other third party material in this article are included in the article's Creative Commons licence, unless indicated otherwise in a credit line to the material. If material is not included in the article's Creative Commons licence and your intended use is not permitted by statutory regulation or exceeds the permitted use, you will need to obtain permission directly from the copyright holder. To view a copy of this licence, visit http://creativecommons.org/licenses/by/4.0/ The Creative Commons Public Domain Dedication waiver (http://creativecommons.org/publicdomain/zero/1.0/) applies to the data made available in this article, unless otherwise stated in a credit line to the data. 
emphasized. Synchronicity refers whether students are following a group pace or individual pace [12]. Therefore, the above dimensions should be taken into account in the blended learning environments. An important point in the blended learning is that blending the potential of face-to-face and online education environments should be in line with increasing flexibility and achieving the learning goals. Hence, the learning environment should promote independence in learning, participation, interaction, self-assessment and cooperation [11]. Blended learning encourages learners to perform problem solving and confront challenges related to learning and sharing the learning experiences [13]. This approach also plays a significant role in enhancing students' knowledge and skills and flexibility in the teaching-learning process [5]. According to the results of studies by Liu et al. (2016), Chen et al. (2020), Rowe et al. (2012), and Morton et al. (2016), blended learning has a positive effect on enhancing the learning experience and deep learning in medical education courses [13-16]. The results of a meta-analysis showed that blended learning had a positive effect on knowledge acquisition in the health sciences [17]. The findings of another study showed that blended learning enabled students to use different learning styles [5].

Most comparative studies have shown that blended learning is more effective than the face-to-face or online learning approaches [17-19]. Successful use of the blended learning approach in the curriculum requires students' readiness to accept it. Therefore, it is important to identify the social, psychological, cultural and pedagogical factors that may influence the acceptance of blended learning. Zhao \& Yuan (2010) showed that elearning adaptability, perceived usefulness, perceived ease of use and on time teacher's feed-back were the most important factors affecting learner satisfaction with using the blended learning approach [20]. Garcia et al. (2014) reported that the outcome expectancy, facilitating conditions and social influence had a positive impact on the behavioral intention to use blended learning [21]. The results of Tang \& Chaw (2013) showed that variables such as attitudes toward online learning, study management, online interaction and learning flexibility were positively correlated with students' readiness for blended learning [22]. Yeou (2016) reported that computer self-efficacy and perceived usefulness had an important role in the acceptance of blended learning [23]. The findings of $\mathrm{Wu}$ and Liu (2013) showed the positive effect of learning atmosphere, perceived enjoyment, perceived usefulness, system performance, social interaction, content specificity, and performance expectation on the students' satisfaction with blended learning [8].

As indicated above, blended learning is an effective approach in universities [20]. Therefore, it is important to identify the key factors affecting its acceptance. Considering the paucity of knowledge about the topic of the present research, this study was conducted to identify the factors affecting students' behavioral intention to use blended learning in medical education based on the unified theory of acceptance and use of technology 2 (UTAUT2) [24, 25]. In the following section, we will discuss the UTAUT2 and conceptual model constructs.

\section{Theoretical background}

The UTAUT model is one of the most important models in the field of technology adoption which has been developed by Venkatesh et al. (2003) [26]. This model is a new form of the technology acceptance model. The UTAUT model analyzes the users' behavioral intention to use a technology [16]. The evidence shows that UTAUT explains $70 \%$ of the variance in the users' behavioral intention to adopt a technology [23, 24]. This model consists of four main constructs regarding the intention and behavior of using a technology, including performance expectancy, effort expectancy, social influences and facilitating conditions [26]. The UTAUT2 framework was designed by Venkatesh et al. (2012) based on the original version of the UTAUT model [24]. The UTAUT2 has other constructs such as price value, hedonic motivation and habit $[24,25]$. The next section describes the model constructs designed based on the UTAUT2 framework (Fig. 1).

\section{Performance expectancy (PE)}

$\mathrm{PE}$ is defined as "the degree to which an individual believes that using system will help him or her to gain a profit in performance" [24]. In this study, performance expectancy refers to the learners' belief that using blended learning is helpful. The results of some studies have indicated the positive effect of PE on the behavioral intention [27-31].

\section{Effort expectancy (EE)}

$E E$ is defined as "the degree of simplicity and ease of use of a system" [26]. This construct is similar to the construct of ease of use perceived in the technology acceptance model. Some studies have indicated that EE may predict behavioral intention to use the elearning system $[27,28]$.

\section{Social influence (SI)}

SI is defined as "the degree to which an individual perceives that others (such as peers and faculty members) believe he or she should use a modern system or a new approach in learning" [26]. Several studies have shown that SI has a significant influence on the behavioral intention of adopting a system [21, 32, 33]. 


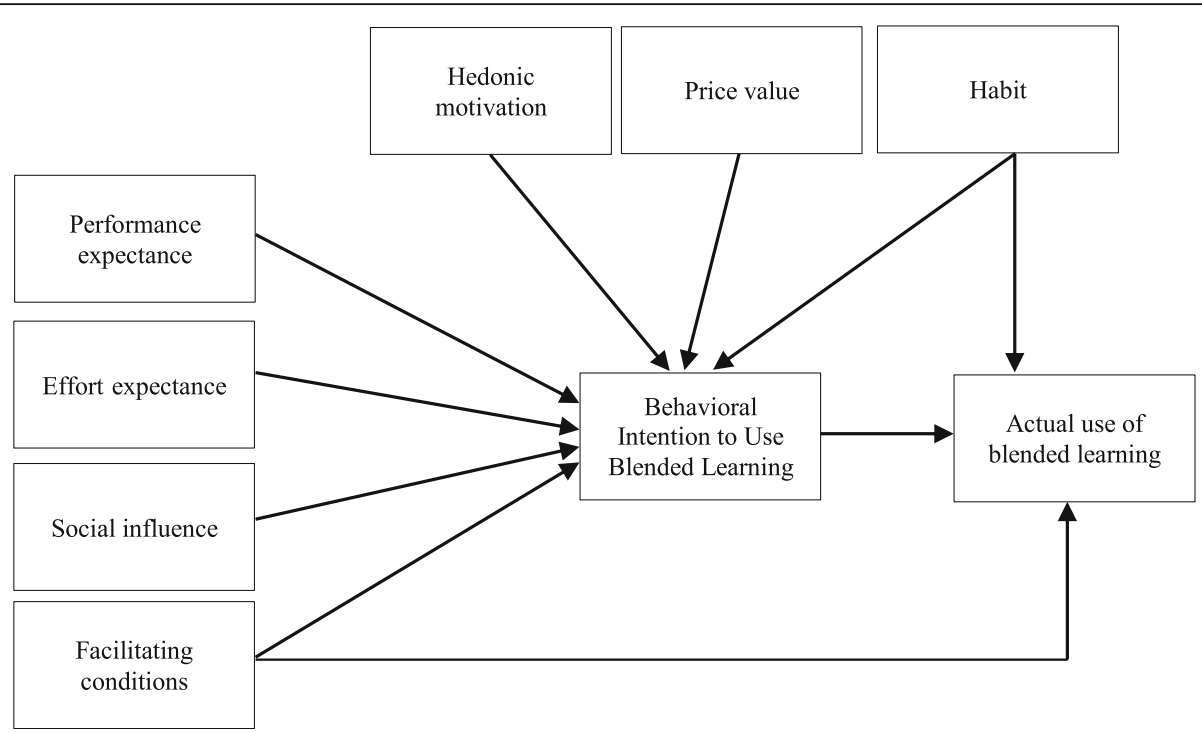

Fig. 1 Research model, adapted from UTAUT2

\section{Facilitating conditions (FC)}

FC expresses "the learner's insights into the existence of technological and organizational infrastructure and equipment to support the use of a system" [33]. In this regard, Sattari et al. (2017) showed that FC had a significant effect on the behavioral intention and use of elearning system [34]. However, Hoque and Sorwar (2017) reported that FC had no significant effect on the users' behavioral intention to use the mobile health service [29].

\section{Hedonic motivation (HM)}

HM is a new construct in the UTAUT2. This construct is defined as "the user's pleasure of using a system" [25]. According to studies, HM is one of the important factors in predicting the intention to use e-learning and mobile learning [32, 33].

\section{Price value (PV)}

This construct is defined as "the learners' understanding of a trade-off between the perceived benefits of system and the monetary cost paid for the adoption of system [25]. If the benefits of acceptance of blended learning are perceived to be greater than the monetary cost, students are more likely to accept it. In this regard, Moorthy et al. (2019) reported that PV had a positive effect on the behavioral intention to use mobile learning [33].

\section{Habit (HT)}

HT is defined as "a students' degree of tendency to perform habitual behaviors in the teaching-learning process". This construct is rooted in one's past experiences [25]. A person's favorable experiences in using a system automatically lead to the formation of a positive belief $[35,36]$. Some studies have shown that HT has a positive influence on the behavioral intention [24, 32, 33].

\section{Behavioral intention (BI)}

BI means the likelihood of a person to use a system. The actual use of a system occurs when a person intends to use it. Evidence suggest that BI has a direct impact on the actual use of system $[26,30,36]$.

\section{Study hypotheses}

H1: The seven factors of the UTAUT2 model will have a positive influence on student's behavioral intention to use blended learning.

H2: Students' behavioral intention to use blended learning will have a positive influence on the actual use of blended learning.

\section{Methods}

This study was designed as a cross sectional, correlational research.

\section{Sample and sampling method}

The study population consisted of all students of Kermanshah University of Medical Sciences (KUMS), Kermanshah, Iran. The optimal sample size was determined to be 230 people using the correlation coefficient formula $(n=230)$. Samples were selected by stratified random sampling method. The sampling stratum included the schools of KUMS. Sampling was performed in each stratum by stratified random method and using the table of random numbers. After distributing the questionnaires among the samples, 225 questionnaires 
were finally collected. The response rate was calculated to be $97 \%$. The inclusion criteria comprised students' willingness to participate in the study and studying in the second semester of the academic year 2019-2020. The exclusion criterion included the incomplete questionnaires.

\section{Instrument development}

Data were collected by a two-part questionnaire. The first section included demographic items about gender and age. The second section included blended learning items. The questionnaire items were designed based on the UTAUT2 framework. In order to design the questionnaire items, we examined the questionnaires based on the UTAUT2 used in other studies $[25,27,28,37$, 38]. Finally, we designed a questionnaire with 31 items and 9 constructs, including PE (5 items), EE (4 items), SI (4 items), FC (3 items), HM (4 items), PV (3 items), HT (4 items), BI (2 items) and actual use of behavior (2 items). The samples provided their responses on a 5point Likert scale from 1 (strongly disagree) to 5 (strongly agree). The content validity and face validity of the questionnaire were evaluated by eight experts and researchers in the field of medical education, blended learning and e-learning. The validity of the final version of the questionnaire was assessed using Content Validity Indices (CVI) and Content Validity Ratio (CVR), which were 0.87 and 0.84 , respectively. To determine the internal consistency, 35 questionnaires were distributed among the students. Then, the internal consistency of the questionnaire was calculated by the Cronbach's alpha coefficient (0.942).

\section{Statistical analysis}

The data were analyzed by SPSS (version 18.0) and AMOS (version 23.0) software. The validity of the model constructs was determined by two types of validity, including convergent validity and discriminant validity. The convergent validity was assessed using Factor Loadings (FL), Cronbach's Alpha (CA), Composite Reliability (CR) and Average Variance Extracted (AVE). The acceptable levels were found to be greater than 0.70 for FL, CA and CR and above 0.50 for AVE $[39,40]$. The discriminant validity was assessed by comparing the correlation coefficients between the constructs and the square root of the AVE.

The $\mathrm{CR}$ index was calculated by the formula $C R=$ $(\Sigma F l) 2 /(\Sigma F l) 2+(\Sigma 1-f l) 2$ and the AVE index was calculated by the formula $A V E=\Sigma(f l 2) / n[41,42]$. The Structural Equation Modeling (SEM) was used to analyze the study hypotheses. The significant level was set at $P \leq 0.05$.

\section{Procedures}

This study was conducted in Kermanshah, Iran in 2019. At first, we obtained the approval of the research deputy and the National Agency for Strategic Research (NASR) in medical education at KUMS. To get the list of students, we visited the department of education of each school of KUMS. Then, the students' list was numbered, and samples were selected based on the table of random numbers. After selecting the samples, according to their classroom schedule, the researcher attended the schools to distribute the questionnaires. The research objectives were explained to the participants and their consent to participate in the study was taken. Next, the questionnaires were given to them to complete.

\section{Ethical considerations}

This study was conducted in accordance with the ethical considerations of the Helsinki declaration and approved by KUMS and NASR. In line with ethical requirements, the objectives of the study were explained to the participants. Furthermore, written informed consent was obtained from all of them.

\section{Results}

The demographic characteristics of the students are given in Table 1. Of the 225 students participating in the study, $55 \%$ were female and $45 \%$ were male. The majority of students were in the age range of $20-22(n=121$, $53.8 \%$ ). Their mean age was 23 years. (Table 1 ).

The results of convergent validity are presented in Table 2. In order to evaluate convergent validity, the FL, CA, CR and AVE values were calculated. FL in all items were higher than 0.70 . For all constructs, the CA reliability coefficients were higher than 0.70 . In addition, the $\mathrm{CR}$ and AVE indexes were above 0.70 and above 0.50 for all constructs, respectively (Table 2). According to these results, convergent validity was at an optimal level. The results of discriminant validity are presented in Table 3. This index was evaluated using the square roots of the AVE. If the square root of the AVE of a factor is greater than the correlation coefficient of the factor, it can be stated that the questionnaire has good discriminant validity [41, 42]. In this study, the results showed that the questionnaire had excellent discriminant validity (Table 3 ).

Table 1 Demographic characteristic of respondents

\begin{tabular}{lll}
\hline Variable & & $\mathbf{N}(\%)$ \\
\hline Gender & Male & $45 \%$ \\
& Female & $55 \%$ \\
Age (years old) & $20-22$ & $121(53.8 \%)$ \\
& $23-25$ & $89(39.6 \%)$ \\
& $26 \leq$ & $15(6.7 \%)$ \\
\hline
\end{tabular}


Table 2 Measurement model results

\begin{tabular}{|c|c|c|c|c|c|}
\hline Construct & Item & Factor Loading & Cronbach's alpha & CR & AVE \\
\hline \multirow[t]{5}{*}{ Performance expectancy (PE) } & PE1 & 0.87 & 0.95 & 0.931 & 0.840 \\
\hline & PE2 & 0.91 & & & \\
\hline & PE3 & 0.95 & & & \\
\hline & PE4 & 0.92 & & & \\
\hline & PE5 & 0.93 & & & \\
\hline \multirow[t]{4}{*}{ Effort expectancy (EE) } & EE1 & 0.84 & 0.88 & 0.893 & 0.678 \\
\hline & EE2 & 0.81 & & & \\
\hline & EE3 & 0.92 & & & \\
\hline & EE4 & 0.71 & & & \\
\hline \multirow[t]{4}{*}{ Social influence (SI) } & SI1 & 0.87 & 0.91 & 0.92 & 0.748 \\
\hline & $\mathrm{S} 12$ & 0.95 & & & \\
\hline & $\mathrm{SI} 3$ & 0.87 & & & \\
\hline & $\mathrm{S} 14$ & 0.76 & & & \\
\hline \multirow[t]{3}{*}{ Facilitating conditions (FC) } & FC1 & 0.86 & 0.81 & 0.870 & 0.692 \\
\hline & FC2 & 0.88 & & & \\
\hline & FC3 & 0.75 & & & \\
\hline \multirow[t]{4}{*}{ Hedonic motivation (HM) } & HM1 & 0.84 & 0.82 & 0.842 & 0.572 \\
\hline & $\mathrm{HM} 2$ & 0.75 & & & \\
\hline & HM3 & 0.73 & & & \\
\hline & HM4 & 0.70 & & & \\
\hline \multirow[t]{3}{*}{ Price value (PV) } & PV1 & 0.94 & 0.92 & 0.935 & 0.828 \\
\hline & PV2 & 0.89 & & & \\
\hline & PV3 & 0.90 & & & \\
\hline \multirow[t]{4}{*}{ Habit $(H T)$} & HT1 & 0.86 & 0.90 & 0.902 & 0.698 \\
\hline & $\mathrm{HT} 2$ & 0.86 & & & \\
\hline & HT3 & 0.85 & & & \\
\hline & HT4 & 0.77 & & & \\
\hline \multirow[t]{2}{*}{ Behavioral intention (BI) } & Bl1 & 0.78 & 0.82 & 0.835 & 0.718 \\
\hline & $\mathrm{B} 12$ & 0.91 & & & \\
\hline \multirow[t]{2}{*}{ Use behavior (UB) } & UB1 & 0.71 & 0.74 & 0.752 & 0.604 \\
\hline & UB2 & 0.84 & & & \\
\hline
\end{tabular}

Table 3 Discriminant validity results

\begin{tabular}{|c|c|c|c|c|c|c|c|c|c|}
\hline Construct & PE & $\mathrm{EE}$ & SI & FC & $\mathrm{HM}$ & PV & HT & $\mathrm{BI}$ & UB \\
\hline$P E$ & 0.916 & & & & & & & & \\
\hline $\mathrm{EE}$ & 0.227 & 0.823 & & & & & & & \\
\hline SI & 0.272 & 0.308 & 0.864 & & & & & & \\
\hline FC & 0.282 & 0.140 & 0.204 & 0.831 & & & & & \\
\hline HM & 0.191 & 0.878 & 0.262 & 0.151 & 0.756 & & & & \\
\hline PV & 0.217 & 0.182 & 0.053 & 0.130 & 0.160 & 0.909 & & & \\
\hline HT & 0.232 & 0.607 & 0.213 & 0.077 & 0.550 & 0.162 & 0.835 & & \\
\hline $\mathrm{Bl}$ & 0.320 & 0.701 & 0.310 & 0.251 & 0.726 & 0.217 & 0.486 & 0.847 & \\
\hline UB & 0.174 & 0.623 & 0.241 & 0.086 & 0.670 & 0.096 & 0.439 & 0.703 & 0.777 \\
\hline
\end{tabular}


The results of the structural model test are presented in Fig. 2 . The PE $(\beta=0.225, P \leq 0.01)$, $\mathrm{EE}(\beta=0.679, \mathrm{P} \leq$ $0.01)$, SI $(\beta=0.241, P \leq 0.01)$, FC $(\beta=0.156, P \leq 0.01)$, HM $(\beta=0.657, P \leq 0.01), P V(\beta=0.142, P \leq 0.01)$ and HT $(\beta=0.463, P \leq 0.01)$ constructs had a significantly positive effect on the students' behavioral intention to use blended learning. HT had a significantly positive effect on the students' use of blended learning ( $\beta=0.435$, $\mathrm{P} \leq 0.01$ ). In this model, FC had no significant effect on the students' use of blended learning. Further, the students' behavioral intention to use blended learning had a significantly positive effect on the actual use of blended learning $(\beta=0.645, \mathrm{P} \leq 0.01)$ (Fig. 2).

\section{Discussion}

This study examined the factors affecting the acceptance of blended learning in medical education based on the unified theory of acceptance and use of technology 2 (UTAUT2) framework.

The results revealed that performance expectancy (PE) had a significantly positive effect on the students' behavioral intention to use blended learning. This finding was in line with the findings of Hoque and Sorwar (2017) and Suki and Suki $(2017)$ [29, 38]. Additionally, Abdekhoda et al. (2016) reported that PE had a significantly direct effect on the use of e-learning [27]. Therefore, the use of blended learning system in medical education is useful and valuable.

Our study showed that effort expectancy (EE) had a significantly positive effect on the students' behavioral intention to use blended learning. The results of other studies confirm this finding [27-29]. In this regard, results of a study revealed that EE had a significant effect on the use of animation and storytelling [38]. Accordingly, the teaching-learning process seems to be easier in a blended learning environment.

Social influence (SI) had a significantly positive effect on the students' behavioral intention to use blended learning. This finding was consistent with the results of other studies [21, 29, 34, 38]. Similarly, Ain et al. (2016) reported that SI had a positive effect on the use of learning management system [43]. The university management system and the attitudes of the faculty members and students are among the factors that shape the social and cultural atmosphere of the university. We believe that the socio-cultural atmosphere can play a role in supporting and encouraging students to use the blended learning system.

Facilitating Conditions (FC) had a significant effect on the students' behavioral intention to use blended learning. However, this construct had no significant effect on the students' actual use of blended learning. The results of the studies by Abdekhoda et al. (2016) and Tarhni et al. (2017) [27, 28] also showed that FC had no effect on the acceptance of e-learning. In our opinion, software and hardware infrastructures play a very important role in the students' behavioral intention to use of blended learning. Students should be provided with technological support such as high-speed internet and advanced computers to use the blended learning system. They should also have access to sufficient resources and information about blended learning. Effective and successful implementation of the blended learning system requires good governance in higher education and advanced

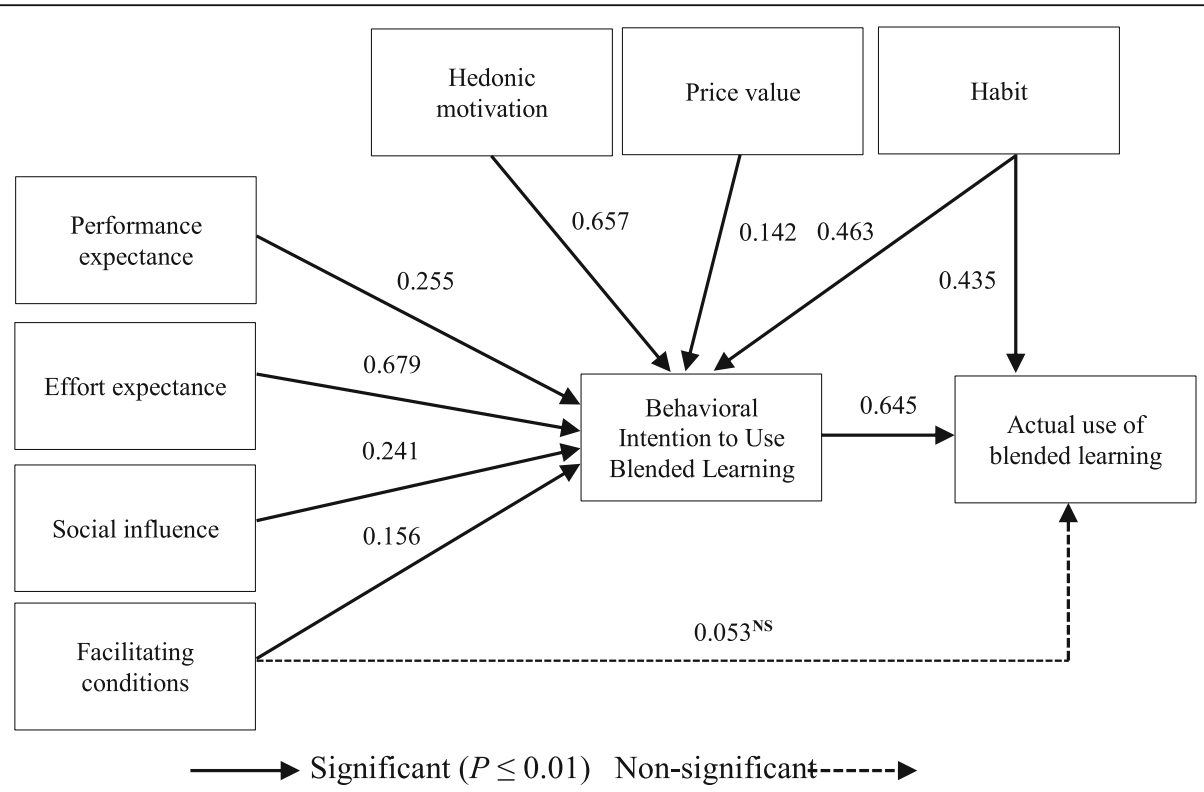

Fig. 2 Structural model results 
Information and Communication Technology (ICT) infrastructure [44]. Hedonic motivation (HM) had a significantly positive impact on the students' behavioral intention to use blended learning. This was in line with the findings of Tarhni et al. (2017) and Moorthy et al. (2017) [28, 33]. Moorthy et al.'s (2017) study showed that HM had a significant correlation with behavioral intention to use mobile learning [33]. Enjoyable learning experiences are an important factor in using blended learning. A user-friendly environment and e-content have a significant impact on creating enjoyable learning experiences [45]. Therefore, educational designers should pay attention to these features.

This study found that price value (PV) had a significantly positive impact on the students' behavioral intention to use blended learning. According to our findings, from the perspective of the Iranian students, inexpensive access to the blended learning materials and the use of the Internet were important factors involved in the acceptance of blended learning. This result is consistent with the findings of the study of Moorthy et al. (2019) in the Malaysian students [33]. Tarhini et al. (2017) conducted a research on the acceptance of elearning by English students [28]. Their study showed that PV had no effect on the acceptance of e-learning. The results of another study [46] showed that from the perspective of American and Qatari students, PV had no effect on the acceptance of e-learning. We believe that different economic and social conditions in the developed and developing countries affect the students' views about this factor.

According to the findings of this study, habit (HT) had a positive effect on the students' intention to use blended learning. In addition, HT had a positive effect on the students' actual use of blended learning. This was in line with the results of Tarhni (2017) and Moorthy et al. (2017) [28, 33]. Venkatesh et al. (2012) revealed that the routine use of a technology had a significant effect on its adoption [24]. Overall, our study showed that the behavioral intention to use blended learning had a significant influence on the students' actual use of blended learning. Our results were consistent with the findings of other studies [29, 38, 47, 48]. Behavioral intention predicted the actual use of blended learning. The actual use of blended learning also depended on the students' behavioral intention to use it.

In summary, our findings showed that Iranian students were willing to use the blended learning system to improve the quality of their learning experiences. According to the UTAUT2 framework, studies have been conducted on students from other countries, including Qatar and the United States [46], the United Kingdom [28], Malaysia [33], Jordan [49], China [50] and Spain [51]. We believe that students in the developed and developing countries have different economic, social and cultural backgrounds. These different conditions may play an important role in the students' intention to adopt a new learning system. In Iran as a developing country, blended learning is an emerging approach in its universities. Therefore, it is recommended to conduct other studies on blended learning.

This study had some limitations. A self-reporting scale was used to assess the behavioral intention to use blended learning. This method of data collection might have affected the accuracy of the results. Qualitative methods are suggested to be used in the future studies. In this study, we identified some factors affecting the acceptance of blended learning using the UTAUT2 framework. Future studies are suggested to investigate the influence of other factors such as attitude toward blended learning, technology anxiety, experience, self-efficacy, compatibility and resistance to change on the behavioral intention to use blended learning. In addition, it is necessary to analyze the role of moderator variables such as sex, age, experience and voluntariness in the future studies. The present study was conducted on the students of neo university, so the findings may not be generalizable to other universities. Given the infrastructure differences between universities in technological and pedagogical domains, we suggest that this study be conducted in other universities.

\section{Conclusion}

The results of the current study revealed that the model designed based on the unified theory of acceptance and use of technology 2 (UTAUT2) has good potential for identifying the factors influencing the use of blended learning in medical education. The performance expectancy, effort expectancy, social influence, facilitation conditions, hedonic motivation, price value, and habit constructs had a significantly positive effect on the students' intention to use blended learning. A review of the literature showed that the findings of the study were consistent with some studies. This study provides a good reference for further research on blended learning in medical education. The results showed that individualpsychological factors such as performance expectancy and effort expectancy, organizational factors such as facilitation conditions and social factors such as social influence in the UTAUT2 have a significant effect on the students' behavioral intention to use blended learning. Providing a social context and organizational support and changing the students' psychological attitudes toward new learning approaches are essential steps involved in the successful implementation of the blended learning system. 


\section{Abbreviations}

UTAUT2: Unified Theory of Acceptance and Use of Technology 2; PE: Performance expectance; EE: Effort expectance; SI: Social influence; FC: Facilitating conditions; HM: Hedonic motivation; PV: Price value; HA: Habit; BI: Behavioral intention; UB: Use behavior; KUMS: Kermanshah University of Medical Sciences; SPSS: Statistical Package In Social Sciences; AMOS: Analysis of Moment Structures; FL: Factors loadings; CR: composite reliability; AVE: average variance extracted; CA: Cronbach's alpha; CVI: content validity indices; CVR: Content Validity Ratio

\section{Acknowledgments}

The authors would like to thank National Agency for Strategic Research in Medical Education. The authors also thank the students who participated in this study. We highly appreciate the Clinical Research Development Center of Imam Reza Hospital affiliated to Kermanshah University of Medical Sciences for their wise advice.

\section{Authors' contributions}

SMA, AK, and NR contributed in designing the proposal, SMA and AK collected the data, NR and SMA contributed to data analyzed. The final manuscript was written by SMA, AK and NR. All authors read and approved the final manuscript.

\section{Funding}

This project was funded by the National Agency for Strategic Research in Medical Education. Tehran. Iran (Grant No. 970115). The budget was spent on sampling and conducting the study.

\section{Availability of data and materials}

The datasets and analyzed during the present research are available from the corresponding author on reasonable request.

\section{Ethics approval and consent to participate}

This study was approved by the research ethics committee of KUMS and National Agency for Strategic Research in Medical Education. A written informed consent was obtained from all of the participants.

\section{Consent for publication}

Not applicable.

\section{Competing interests}

The authors declare that they have no competing interests.

\section{Author details}

${ }^{1}$ Medical Education and Development Center, Arak University of Medical Sciences, Arak, Iran. ${ }^{2}$ Department of Health Education and promotion, Faculty of Health, Arak University of Medical Sciences, Arak, Iran. ${ }^{3}$ Clinical Research Development Center of Imam Reza Hospital, Kermanshah University of Medical Sciences, Kermanshah, Iran.

\section{Received: 5 May 2020 Accepted: 9 October 2020}

\section{Published online: 16 October 2020}

\section{References}

1. Herbert C, Velan GM, Pryor WM, Kumar RK. A model for the use of blended learning in large group teaching sessions. BMC Med Educ. 2017;17(1):197.

2. Salim H, Lee PY, Ghazali SS, Ching SM, Ali H, Shamsuddin NH, et al. Perceptions toward a pilot project on blended learning in Malaysian family medicine postgraduate training: a qualitative study. BMC Med Educ. 2018; 18(1):206.

3. Ilic D, Hart W, Fiddes P, Misso M, Villanueva E. Adopting a blended learning approach to teaching evidence based medicine: a mixed methods study. BMC Med Educ. 2013;13(1):169.

4. Langenau EE, Lee R, Fults M. Blended learning educational format for thirdyear pediatrics clinical rotation. J Am Osteopath Assoc. 2017;117(4):234-43.

5. Coyne E, Rands H, Frommolt V, Kain V, Plugge M, Mitchell M. Investigation of blended learning video resources to teach health students clinical skills: an integrative review. Nurse Educ Today. 2018;63:101-7.

6. Garrison DR, Vaughan ND. Blended learning in higher education: framework, principles, and guidelines. San Francisco: John Wiley \& Sons; Published by Jossey-Bass A Wiley Imprint; 2008.
7. Graham CR. Emerging practice and research in blended learning. Handbook of distance education. 2013;3:333-50.

8. Wu J, Liu W. An empirical investigation of the critical factors affecting students' satisfaction in EFL blended learning. J Language Teach Res. 2013; 4(1):176-85.

9. Medina LC. Blended learning: deficits and prospects in higher education. Aust J Educ Technol. 2018;34(1):42-56.

10. Keržič $\mathrm{D}$, Tomaževič $\mathrm{N}$, Aristovnik A, Umek L. Exploring critical factors of the perceived usefulness of blended learning for higher education students. PloS one. 2019;14(11):e0223767.

11. Seraji F, Attaran M, Azizi SM. Blended learning researches in Iran: several fundamental criticisms. Digital Educ Rev. 2019;36:190-206.

12. Margulieux LE, Bujak KR, McCracken WM, Majerich D. Hybrid, blended, flipped, and inverted: Defining terms in a two dimensional taxonomy. In: Proceedings of the 12th Annual Hawaii International Conference on Education. Honolulu; 2014. Available from: https://c21u.gatech.edu/sites/ default/files/papers/HICE\%20Conference\%20Proceedings_1556_with\%2 0citation\%5B4\%5D.pdf.

13. Liu Q, Peng W, Zhang F, Hu R, Li Y, Yan W. The effectiveness of blended learning in health professions: systematic review and meta-analysis. J Med Internet Res. 2016;18(1):e2.

14. Chen J, Zhou J, Wang Y, Qi G, Xia C, Mo G, et al. Blended learning in basic medical laboratory courses improves medical students' abilities in self-learning, understanding, and problem solving. Adv Physiol Educ. 2020;44(1):9-14.

15. Rowe M, Frantz J, Bozalek V. The role of blended learning in the clinical education of healthcare students: a systematic review. Med Teach. 2012; 34(4):e216-e21.

16. Morton CE, Saleh SN, Smith SF, Hemani A, Ameen A, Bennie TD, et al. Blended learning: how can we optimise undergraduate student engagement? BMC Med Educ. 2016;16(1):195.

17. Kiviniemi MT. Effects of a blended learning approach on student outcomes in a graduate-level public health course. BMC Med Educ. 2014;14(1):47.

18. Bazelais $P$, Doleck T. Blended learning and traditional learning: a comparative study of college mechanics courses. Educ Inf Technol. 2018; 23(6):2889-900.

19. Karamizadeh Z, Zarifsanayei N, Faghihi A, Mohammadi H, Habibi M. The study of effectiveness of blended learning approach for medical training courses. Iran Red Crescent Med J. 2012;14(1):41.

20. Zhao G, Yuan S. Key factors of effecting blended learning satisfaction: a study on Peking University students. International Conference on Hybrid Learning. Berlin: Springer; 2010. pp. 282-95.

21. García AVM, del Dujo ÁG, Rodríguez JMM. Factores determinantes de adopción de blended learning en educación superior. Adaptación del modelo UTAUT. Educación XX1. 2014;17(2):217-40.

22. Tang C, Chaw L. Readiness for blended learning: understanding attitude of university students. Int J Cyber Soc Educ. 2013;6(2):79-100.

23. Yeou M. An investigation of students' acceptance of Moodle in a blended learning setting using technology acceptance model. J Educ Technol Syst. 2016;44(3):300-18

24. Venkatesh $\mathrm{V}$, Thong JY, Xu X. Consumer acceptance and use of information technology: extending the unified theory of acceptance and use of technology. MIS Q. 2012;36(1):157-78.

25. Chao C-M. Factors determining the behavioral intention to use mobile learning: an application and extension of the UTAUT model. Front Psychol. 2019:10:1652.

26. Venkatesh V, Morris MG, Davis GB, Davis FD. User acceptance of information technology: toward a unified view. MIS Q. 2003;27(3):425-78.

27. Abdekhoda M, Dehnad A, Mirsaeed SJG, Gavgani VZ. Factors influencing the adoption of E-learning in Tabriz University of Medical Sciences. Med J Islamic Republic of Iran. 2016;30:457.

28. Tarhini A, Masa'deh R, Al-Busaidi KA, Mohammed AB, Magableh M. Factors influencing students' adoption of e-learning: a structural equation modeling approach. J Int Educ Bus. 2017;10(2):164-82.

29. Hoque R, Sorwar G. Understanding factors influencing the adoption of mHealth by the elderly: an extension of the UTAUT model. Int J Med Inform. 2017:101:75-84.

30. Jahanbakhsh M, Peikari HR, Hazhir F, Saghaeiannejad-Isfahani S. An investigation into the effective factors on the acceptance and use of integrated health system in the primary health-care centers. J Edu Health Promot. 2018:7:128. 
31. Šumak B, Šorgo A. The acceptance and use of interactive whiteboards among teachers: differences in UTAUT determinants between pre-and postadopters. Comput Hum Behav. 2016;64:602-20.

32. Nguyen TD, Nguyen DT, Cao TH. Acceptance and use of information system: E-learning based on cloud computing in Vietnam. Information and Communication Technology-EurAsia Conference. Berlin: Springer; 2014. pp. $139-49$.

33. Moorthy K, Yee TT, T'ing LC, Kumaran W. Habit and hedonic motivation are the strongest influences in mobile learning behaviours among higher education students in Malaysia. Aust J Educ Technol. 2019;35(4):174-91.

34. Sattari A, Abdekhoda M, Zarea GV. Determinant factors affecting the webbased training acceptance by health students, applying UTAUT model. Int J Emerg Technol Learn. 2017;12(10):112-26.

35. Huang C-Y, Kao Y-S. UTAUT2 based predictions of factors influencing the technology acceptance of phablets by DNP. Math Probl Eng. 2015:(1):1-23.

36. Limayem M, Hirt SG, Cheung CM. How habit limits the predictive power of intention: The case of information systems continuance. MIS Quarterly. 2007; 31(4):705-37.

37. Ngampornchai A, Adams J. Students' acceptance and readiness for E-learning in northeastern Thailand. Int J Educ Technol High Educ. 2016;13(1):34.

38. Suki NM, Suki NM. Determining students' behavioural intention to use animation and storytelling applying the UTAUT model: the moderating roles of gender and experience level. Int J Manage Educ. 2017;15(3):528-38.

39. Fornell C, Larcker DF. Evaluating structural equation models with unobservable variables and measurement error. J Mark Res. 1981;18(1):39-50.

40. Hair JF, Black WC, Babin BJ, Anderson RE. Multivariate data analysis. Harlow: Pearson Education Limited, Seventh edition, Pearson new international edition. Harlow; 2014.

41. Azizi SM, Khatony A. Investigating factors affecting on medical sciences students' intention to adopt mobile learning. BMC Med Educ. 2019;19(1):381.

42. Cheon J, Lee S, Crooks SM, Song J. An investigation of mobile learning readiness in higher education based on the theory of planned behavior. Comput Educ. 2012:59(3):1054-64.

43. Ain N, Kaur K, Waheed M. The influence of learning value on learning management system use: an extension of UTAUT2. Inf Dev. 2016;32(5): 1306-21.

44. Dewi KC, Ciptayani PI, Surjono HD. Critical success factor for implementing vocational blended learning. J Phys Conf Ser. 2018;953(1):012086.

45. Warnecke E, Pearson S. Medical students' perceptions of using e-learning to enhance the acquisition of consulting skills. Australas Med J. 2011;4(6):300.

46. El-Masri M, Tarhini A. Factors affecting the adoption of e-learning systems in Qatar and USA: extending the unified theory of acceptance and use of technology 2 (UTAUT2). Educ Technol Res Dev. 2017;65(3):743-63.

47. Ravangard R, Kazemi Z, Abbasali SZ, Sharifian R, Monem H. Development of the UTAUT2 model to measure the acceptance of medical laboratory portals by patients in shiraz. Electron Physician. 2017;9(2):3862.

48. Hsu LL, Hsieh SI. Factors affecting metacognition of undergraduate nursing students in a blended learning environment. Int J Nurs Pract. 2014;20(3): 233-41.

49. Dajani D, Hegleh ASA. Behavior intention of animation usage among university students. Heliyon. 2019;5(10):e02536.

50. Liu D, Maimaitijiang R, Gu J, Zhong S, Zhou M, Wu Z, et al. Using the unified theory of acceptance and use of technology (UTAUT) to investigate the intention to use physical activity apps: cross-sectional survey. JMIR mHealth and uHealth. 2019;7(9):e13127.

51. Escobar-Rodríguez T, Carvajal-Trujillo E, Monge-Lozano P. Factors that influence the perceived advantages and relevance of Facebook as a learning tool: An extension of the UTAUT. Aust J Educ Technol. 2014;30(2): $136-51$

\section{Publisher's Note}

Springer Nature remains neutral with regard to jurisdictional claims in published maps and institutional affiliations.

Ready to submit your research? Choose BMC and benefit from:

- fast, convenient online submission

- thorough peer review by experienced researchers in your field

- rapid publication on acceptance

- support for research data, including large and complex data types

- gold Open Access which fosters wider collaboration and increased citations

- maximum visibility for your research: over $100 \mathrm{M}$ website views per year

At $\mathrm{BMC}$, research is always in progress.

Learn more biomedcentral.com/submissions 